\title{
Correction to: Heart rate variability as possible marker of brain damage in neonates with hypoxic ischemic encephalopathy: a systematic review
}

\author{
Iliana Bersani ${ }^{1}$ D Fiammetta Piersigilli $^{2} \cdot$ Diego Gazzolo $^{3} \cdot$ Francesca Campi $^{1} \cdot$ Immacolata Savarese $^{1}$. \\ Andrea Dotta ${ }^{1} \cdot$ Pietro Paolo Tamborrino $^{4} \cdot$ Cinzia Auriti $^{1} \cdot$ Corrado Di Mambro ${ }^{4}$
}

Published online: 10 December 2020

(C) Springer-Verlag GmbH Germany, part of Springer Nature 2020

\section{Correction to: European Journal of Pediatrics} https://doi.org/10.1007/s00431-020-03882-3

The affiliation and contact email address of the second author of the original published version of the above article was incorrect. The author requested to update these as follows:

Fiammetta Piersigilli

Fiammetta.piersigilli@uclouvain.be

Cliniques Universitaires Saint Luc, Université Catholique de Louvain, Bruxelles, Belgium

The original article has been corrected.

Publisher's note Springer Nature remains neutral with regard to jurisdictional claims in published maps and institutional affiliations.

The online version of the original article can be found at https://doi.org/ 10.1007/s00431-020-03882-3

Iliana Bersani

ilianabersani@gmail.com

Fiammetta Piersigilli

Fiammetta.piersigilli@uclouvain.be

Diego Gazzolo

dgazzolo@hotmail.com

Francesca Campi

Francesca.campi@opbg.net

Immacolata Savarese

immacolata.savarese@opbg.net

Andrea Dotta

andrea.dotta@opbg.net

Pietro Paolo Tamborrino

pietropaolotamb@gmail.com
Cinzia Auriti

cinzia.auriti@opbg.net

Corrado Di Mambro

corrado.dimambro@opbg.net

1 Department of Medical and Surgical Neonatology, Bambino Gesù Children's Hospital, Rome, Italy

2 Cliniques Universitaires Saint Luc, Université Catholique de Louvain, Bruxelles, Belgium

3 Neonatal Intensive Care Unit, G. d'Annunzio University, Chieti, Italy

4 Pediatric Cardiology and Cardiac Arrhythmia/Syncope Complex Unit, Department of Pediatric Cardiology and Cardiac Surgery, Bambino Gesù Children's Hospital, Rome, Italy 